\title{
AMBIENTE INSTITUCIONAL E RESPONSABILIDADE SOCIAL CORPORATIVA NA CAFEICULTURA AFRICANA
}

\author{
E. C. SILVA ${ }^{*}$, A. S. AZEVEDO, L. G. CASTRO JUNIOR \\ Universidade Federal de Lavras \\ educesar_muz@hotmail.com*
}

Submetido 25/01/2018 - Aceito 19/02/2018

DOI: $10.15628 /$ holos. 2018.6860

\begin{abstract}
RESUMO
A cafeicultura é uma atividade econômica importante para os agricultores de muitos países da América, África, Ásia e Oceania. Entretanto, a cafeicultura africana perdeu participação no mercado mundial nas últimas décadas. Este trabalho analisou o declínio da cafeicultura africana sob a perspectiva da Nova Economia Institucional (NEI). O trabalho foi feito em duas etapas. Na primeira, foi realizada uma pesquisa bibliográfica sobre a história política de quatro países que eram os mais importantes produtores de café da África na década de 1960, a saber: Angola, Etiópia, Costa do Marfim e Uganda. Na segunda etapa, foi realizada uma pesquisa documental sobre ações de Responsabilidade Social Corporativa (RSC) de companhias multinacionais de café nos países africanos em anos recentes. Os dados obtidos foram apurados por meio da análise de conteúdo e interpretados a partir dos pressupostos da NEI. Os resultados indicam que houve grande instabilidade política nos quatros países analisados, algo que impede o desenvolvimento de instituições capazes de fomentar o desenvolvimento econômico. Nesse contexto, os resultados mostram que a ação das empresas multinacionais preenche um vazio deixado pelo Estado.
\end{abstract}

PALAVRAS-CHAVE: Instituições, Democracia, Café, Sustentabilidade, Desenvolvimento.

\section{INSTITUTIONAL ENVIROMENT AND CORPORATE SOCIAL RESPONSIBILITY IN AFRICAN COFFEE SECTOR}

\begin{abstract}
Coffee farming is an important economic activity for farmers in many countries in America, Africa, Asia and Oceania. However, African coffee production has lost its share of the world market in recent decades. This paper analyzed the decline of African coffee production from the perspective of the New Institutional Economics (NIE). The research was done in two stages. First, a bibliographical research was carried out on the political history of four countries that were the most important coffee producers in Africa in the 1960s: Angola, Ethiopia, Côte d'Ivoire and Uganda. In the second stage, a
\end{abstract}

documentary survey was conducted on Corporate Social Responsibility (CSR) actions of multinational coffee companies in African countries in recent years. The data obtained were processed with contente analysis and nterpreted from the assumptions of the NIE. The results indicate that there was great political instability in the four countries analyzed, something that prevents the development of institutions capable of fostering economic development. In this context, the results show that the action of multinational companies fills a void left by the State.

KEYWORDS: Institutions, Democracy, Coffee, Sustainability, Development. 


\section{INTRODUÇÃO}

O café é uma das bebidas mais populares do mundo. Ela é preparada a partir dos grãos de duas espécies principais de cafeeiro, Coffea arabica e Coffea canephora. Ambas são cultivadas nas regiões quentes do planeta, entre os trópicos de Câncer e Capricórnio, em uma extensa faixa do globo conhecida como "cinturão do café".

Mais de 50 países produzem o grão. Eles estão distribuídos pela América, África, Ásia e Oceania (International Coffee Organization - ICO, 2017a). Além do clima propício para o cultivo, esses países compartilham entre si o fato de serem nações pobres ou em desenvolvimento. Neles, o cultivo de café gera emprego e renda para milhões de pessoas (Pendergrast, 2010). A maior parte da produção é exportada para as nações desenvolvidas (ICO, 2017b), o que coloca os cafeicultores dentro das modernas cadeias globais de suprimentos.

Estima-se que existam cerca de 25 milhões de pequenos cafeicultores ao redor do mundo, responsáveis por 70\% da produção global (ICO, 2017c). Para eles, o café não é uma cultura de subsistência. Tipicamente, pequenos agricultores produzem para o seu próprio sustento e vendem o excedente, mas a cafeicultura é orientada para a exportação e geração de renda (Topik, 2003).

A safra global de café cresceu consideravelmente nas últimas décadas, acompanhando o aumento da demanda. Porém, os países africanos não seguiram essa tendência. Segundo dados do United States Department of Agriculture - USDA (2017), a produção mundial aumentou $191,2 \%$ entre as safras de $1964 / 1965$ e $2014 / 2015$. No mesmo período, o volume colhido na África caiu 9,4\%. Com isso, a participação do café africano no mercado mundial, que era de $32 \%$, caiu para $10 \%$.

Apesar do declínio, a cafeicultura ainda é uma atividade econômica de grande importância para o continente. Segundo dados da ICO (2015), cerca de 10,9 milhões de agricultores e trabalhadores dependem do café na África. Adicionalmente, o café contribui de maneira significativa para as receitas de exportação de alguns países (ICO, 2015).

Dada a relevância da cafeicultura para a África, o que causou o declínio da atividade? Um estudo elaborado por Ponte (2002) concluiu que a estrutura vigente na cadeia produtiva do café é prejudicial aos países produtores. O autor explica que entre 1962 e 1989 vigoraram acordos entre as nações produtoras que buscavam regular a oferta mundial de café. Como resultado, os preços no mercado internacional eram atrativos aos agricultores. Com fim desses acordos, o mercado passou a operar de maneira livre, o que teria favorecido as grandes empresas de exportação e industrialização do grão em detrimento dos produtores.

A liberalização do mercado cafeeiro impactou todos os países produtores. Mas enquanto as nações africanas apresentaram queda na produção, países como Brasil, Vietnã e Honduras obtiveram grande crescimento desde a década de 1990 (USDA, 2017). Essa diferença de desempenho entre países sugere que podem haver fatores internos interferindo na cafeicultura. Uma chave interpretativa para o problema pode estar na Nova Economia Institucional (NEI), uma escola de pensamento econômico que atribui as diferenças no desenvolvimento econômico dos países às leis e regulações vigentes em cada um. No caso do café, a maneira como cada governo nacional regula a produção pode criar barreiras ou estímulos ao cultivo do grão. 
A NEI também pode contribuir para a compreensão de outro fenômeno que se observa na cafeicultura africana e que parece estar relacionado ao seu declínio. Grandes empresas que industrializam o café, como Nestlé, Jacobs Douwe Egberts e Starbucks, estão investindo em projetos de Responsabilidade Social Corporativa (RSC) para apoiar os produtores africanos (Bureau de Inteligência Competitiva do Café - BICC, 2015). Ações de RSC desenvolvidas pela indústria do café para ajudar os cafeicultores são um fenômeno recente. Segundo Pendergrast (2010), elas tiveram início após 2001, quando a cafeicultura mundial enfrentou uma grave crise decorrente de uma queda nos preços do café. Atualmente, os projetos de RSC destinados aos cafeicultores parecem estar concentrados nos países africanos (BICC, 2015).

Com base no cenário apresentado acima, ficam evidentes duas características da cafeicultura africana: a) o declínio da produção, apesar da importância econômica da atividade; e b) os investimentos de empresas multinacionais, apesar do declínio da produção. A partir delas, chegou-se ao seguinte problema de pesquisa: qual é a relação entre a diminuição da produção africana e o apoio das multinacionais aos cafeicultores do continente?

Assim, o objetivo principal do artigo é investigar as causas da baixa produção de café na África e os determinantes da ação das empresas multinacionais. Assume-se como hipótese que os dois fenômenos estão relacionados, e que ambos são reflexo do ambiente institucional presente nos principais países produtores de café da África.

Os dados foram obtidos por meio de pesquisa bibliográfica sobre a história recente da cafeicultura africana e pesquisa documental sobre as ações de RSC de empresas multinacionais nesse setor. Os dados foram analisados por meio da análise de conteúdo e interpretados à luz da Nova Economia Institucional.

\section{REVISÃO BIBLIOGRÁFICA}

\subsection{Instituições e Ambiente Institucional}

O campo teórico que trata sobre o ambiente institucional e suas influências no processo de desenvolvimento econômico e regional constitui uma das principais abordagens da Nova Economia Institucional (NEI) (Williamson, 1996). A NEI possui como foco o entendimento de como as instituições surgem, operam, evoluem e moldam os diferentes arranjos de produção e troca; além de suas interações com os arranjos institucionais (Ménard \& Shirley, 2005).

Conforme Bueno (2004), os desenvolvimentos teóricos advindos da NEI podem ser divididos em duas principais correntes sendo elas, ambiente institucional e estruturas de governança. Na primeira corrente, os estudos estão centrados na relação existente entre as instituições de uma determinada localidade e seu desempenho econômico. Ela também busca identificar quais instituições são mais propícias para o desenvolvimento econômico regional. Já a segunda corrente tem como objetivo a análise das interações entre as unidades econômicas e como as estruturas de governança são criadas e transformada conforme as transações.

De acordo com Davis, North e Smorodin (1971), o ambiente institucional consiste em um conjunto de regras políticas, sociais e legais fundamentais que estabelecem as bases para a produção, transação e distribuição. Essas regras são denominadas como instituições. Conforme North (1989), instituições são as regras, as formas de executar essas regras e as normas 
comportamentais que estruturam as interações humanas. As instituições são constituídas por restrições formais, como regras, leis e constituições; restrições informais, tais como normas comportamentais, convenções e códigos de conduta autoimpostos e de suas características impositivas. Para North (2010), estes três aspectos juntos determinam a estrutura de incentivos das sociedades e, também, da economia.

Acemoglu (2008) afirma que as instituições atuam como fatores que afetam o desenvolvimento econômico e diferenciam regiões desenvolvidas de regiões com baixo desenvolvimento. Para o autor, as instituições são importantes pela sua influência na estrutura da economia e pela sua garantia no uso mais eficiente dos seus recursos, promovendo maior produtividade e lucros; além de organizar a sociedade de forma a promover seu crescimento ou retardá-lo.

As instituições e o ambiente institucional são capazes de viabilizar ou não as inovações tecnológicas, influenciar na forma como as firmas estão organizadas, interferir no processo de trabalho e nas políticas macroeconômicas; além de induzir as estratégias empresariais e as decisões tomadas pelos agentes (Conceição, 2002). Também é relacionado ao ambiente institucional o tamanho das unidades produtivas, o nível tecnológico, o volume de mão de obra empregado e a remuneração, a produtividade, a quantidade e qualidade dos bens e serviços, e os investimentos em pesquisa e desenvolvimento (Fiani, 2011).

A estrutura de uma economia é influenciada pelas instituições, que organizam a sociedade de forma a promover seu crescimento ou retardá-lo (Acemoglu, 2008). O desenvolvimento não é mais considerado como resultado de uma transformação gradual, mas sim resultado da evolução das instituições e a forma como elas apoiam as relações sociais e comerciais (Klein, 1998). Desse modo, torna-se importante analisar o ambiente institucional e suas instituições para entender o processo de desenvolvimento e o desempenho de uma determinada região.

Acemoglu \& Robinson (2012) apresentam dois tipos de instituições econômicas, as inclusivas e as extrativistas. As instituições econômicas inclusivas promovem as atividades econômicas, o aumento da produtividade e a prosperidade da economia; com a garantia de segurança da propriedade privada, com um sistema jurídico imparcial e uma variedade de serviços públicos que permitam o estabelecimento de contratos e condições igualitárias para todos, além de promover o surgimento de novas empresas. Já as instituições econômicas extrativistas preocupam-se apenas em extrair a renda de um determinado segmento da sociedade para o benefício de outro, além de possuírem características opostas aos das instituições denominadas como inclusivas.

As instituições inclusivas impulsionam os avanços tecnológicos, pois somente instituições econômicas que fomentem a propriedade privada, ofereçam garantia nos contratos, criem condições igualitárias para todos os membros da sociedade, e incentivem e viabilizem o surgimento de novas empresas são capazes de instigar os empreendedores na aplicação de recursos em negócios rentáveis (Acemoglu \& Robinson, 2012).

Infere-se que as instituições econômicas inclusivas trabalham de forma a promover o desenvolvimento econômico, pois proporcionam aos indivíduos da sociedade condições favoráveis para a execução de atividades econômicas prósperas e produtivas; enquanto as 
instituições extrativistas preocupam-se, apenas, em explorar a sociedade sem lhe fornecer garantias e/ou retornos.

Nos últimos anos, estudos empíricos encontraram correlações positivas entre variáveis que medem a qualidade do ambiente institucional e o desenvolvimento econômico. A liberdade econômica, por exemplo, apresenta correlação positiva com o desempenho econômico e indicadores sociais (Williamson \& Mathers, 2011; Belasen \& Hafer, 2012; Hall \& Lawson, 2012; Gehring, 2013; Blau, Brough \& Thomas, 2014; Herrera-Echeverri, Haar \& Tévez-Bretón, 2014).

Outros estudos identificaram a estrutura política dos países, notadamente a existência de democracia, entendida como um processo que garante a liberdade política aos cidadãos e assegura a divisão dos poderes, como fator causador de desenvolvimento (Spaiser et al. 2014; Heo \& Hahm, 2015; Neudorfer, 2015; Ranganathan et al., 2015; Shyam et al., 2015).

Auer (2013) identificou o efeito da geografia e modo de colonização sobre as instituições econômicas. E um estudo encontrou ligação entre a capacidade de um país se recuperar de eventos adversos, mais especificamente terremotos, com a qualidade do ambiente institucional existente antes do evento (Barone \& Mocetti, 2014).

\subsection{Responsabilidade Social Corporativa}

A partir do século $X X$, intensificaram-se as pressões dos consumidores, organizações internacionais e órgãos públicos para que as empresas adotassem ações socialmente responsáveis (Fernandes, 2014).

O surgimento de novas preocupações e expectativas por parte da sociedade em um contexto globalizado e de grandes mudanças industriais; a crescente influência das questões sociais nas decisões relacionadas a investimento, tanto da parte dos consumidores quanto dos investidores; o aumento na preocupação com os danos causados ao meio ambiente pelas organizações; a maior transparência das atividades empresarias, causada pelo desenvolvimento das tecnologias de informação e comunicação que permitem o acesso a tais informações; estão relacionadas como fatores que motivaram a evolução da Responsabilidade Social Corporativa (RSC) no contexto empresarial (Comissão das Comunidades Europeias, 2001).

Diante dessas demandas e das influências geradas por elas, as empresas perceberam a necessidade de realizar atividades que atestam seu compromisso social (Costa, 2005). Dessa maneira, os pressupostos da RSC estão alinhados com as preocupações sociais dos consumidores, com a criação de uma imagem corporativa favorável e com o desenvolvimento de uma relação confiável entre a empresa e as partes interessadas (Yoon, Giirhan-Canli \& Schwarz, 2006).

Atualmente, os debates sobre RSC estão presentes na academia, nas organizações e na sociedade. Porém, de acordo com Kreitlon (2004), há trinta anos tais discussões se mostravam rasas e não recebiam tanta atenção quanto nos dias de hoje. Contudo, os conceitos da RSC são antigos. De acordo com Carroll (1999), a preocupação das empresas com a sociedade remonta há séculos, porém, somente a partir da década de 1950 esses conceitos passaram a ser escritos formalmente. Segundo o autor, o livro de Howard R. Bowen, intitulado Social Responsibilities of the Businessman (1953), deu início aos questionamentos do papel das organizações na sociedade. Em seu trabalho, Bowen (citado por Carroll, 1999) define que a responsabilidade 
social das empresas está relacionada aos valores que elas, a partir de suas decisões, geram para a sociedade.

As discussões sobre RSC foram intensificadas nas décadas seguintes. Segundo Bertoncello \& Chang Júnior (2007), os debates possuíam como ideia principal a ampliação das preocupações das empresas, que não deveriam se limitar apenas a maximização dos lucros, mas também abranger pensamentos voltados para uma melhor utilização dos seus recursos para fins sociais. Ainda de acordo com os autores, a RSC começou a ser integrada aos debates públicos sobre problemas sociais, o que resultou no envolvimento das organizações com movimentos ambientais, o surgimento da preocupação com a segurança do trabalho e a regulamentação governamental.

Mesmo com todas essas discussões, o campo dos negócios e a sociedade ainda não possuíam uma definição sobre RSC. Carroll, com sua obra publicada em 1979, propunha um modelo conceitual tridimensional de desempenho social corporativo. Esse trabalho foi aceito e aprimorado por outros autores (Lee, 2008).

Em sua obra, Carroll (1979) oferece um modelo conceitual que abrange os principais conceitos de RSC desenvolvidos até então, no intuito de auxiliar a compreensão sobre os principais aspectos do desempenho social corporativo. Para o autor, a definição de RSC deve abranger todas as obrigações que as empresas possuem com a sociedade e deve incorporar quatro categorias de responsabilidades, sendo elas econômicas, legais, éticas e discricionárias.

A primeira responsabilidade social das empresas é a econômica. As organizações têm o dever de produzir bens e serviços que atendam a demanda da sociedade e vendê-los com margem de lucro. A responsabilidade legal prevê que as empresas cumpram sua missão econômica de acordo com os requisitos legais. A responsabilidade ética abrange comportamentos e atividades que não são, necessariamente, pautados por leis. Entretanto, a sociedade espera que as empresas respeitem e realizem seus negócios além dos requerimentos legais. Por fim, as responsabilidades discricionárias são aquelas que não estão diretamente ligadas ao negócio e não são exigidas por lei, porém são assumidas de forma voluntária pelas empresas, com programas voltados à filantropia (Carroll, 1979).

Wood (1991) complementa que a ideia básica de RSC relaciona-se ao fato de empresas e sociedade não serem entidades distintas e sim, entrelaçadas, o que faz com que a sociedade espere um comportamento empresarial adequado.

Embora a definição de Carroll seja empregada de forma ampla, ainda existe uma incerteza sobre a definição correta de RSC (Baron, 2001; Dahlsrud, 2008). Com o crescimento do campo, houve a proliferação de abordagens, teorias e terminologias. Termos como sociedade e negócios, políticas públicas e de negócios e gestão dos stakeholders são utilizados para descrever os fenômenos relacionados com a RSC na sociedade (Garriga \& Melé, 2004).

Em muitos casos, a RSC é vista como uma solução para a pobreza global, a exclusão social e a degradação ambiental, além de ser associada a outras disciplinas, tais como gestão de qualidade, marketing, recursos humanos. Cada disciplina possui seu ponto de vista em relação à RSC, alinhado com suas situações e desafios específicos (Van Marrewijk, 2003).

A World Business Council for Sustainable Development (WBCSD) complementa a definição de RSC com a afirmação de que ela consiste no compromisso da empresa em contribuir para o 
desenvolvimento econômico sustentável, trabalhando com os funcionários, suas famílias, a comunidade local e a sociedade em geral com o objetivo de melhorar sua qualidade de vida (WBCSD, 1991).

A Comissão das Comunidades Europeias (2001) divide a RSC em duas dimensões: interna e externa. A dimensão interna preocupa-se com a gestão de recursos humanos, saúde e segurança do trabalho e adaptação à mudança. Também se preocupa com a gestão do impacto ambiental e dos recursos naturais, de forma atenuar possíveis danos ao meio ambiente.

Já a dimensão externa está voltada para comunidades locais, buscando uma melhor integração da empresa com a comunidade por meio de atividades que promovam a questão ambiental, recrutamento de pessoas socialmente excluídas, práticas de cuidado à infância, parceria com a população local, promoção de ações culturais e doações de donativos para a caridade; parceiros comerciais, fornecedores e consumidores, agindo de forma ética com todos; direitos humanos, respeitando a legislação vigente e códigos de conduta que preguem a adoção de práticas que respeitem estes direitos; e preocupações ambientais globais, contribuindo para o desenvolvimento sustentável do planeta (Comissão das Comunidades Europeias, 2001).

Um dos grandes debates sobre a RSC é seu efeito sobre o desempenho financeiro das empresas. A partir de uma meta-análise de 42 estudos sobre o tema, Wang, Dou \& Jia (2016) concluíram que tal efeito existe e é positivo. Outro ponto de grande interesse para os pesquisadores é influência de fatores externos e internos sobre a adoção da RSC. Frynas \& Yamahaki (2016) analisaram 462 artigos publicados entre 1990 e 2014 e concluíram que a análise dos fatores externos predomina na literatura. No entanto, eles sugerem que esse campo de estudos pode se beneficiar de análises com foco nos fatores internos e no papel que os indivíduos exercem dentro das organizações.

No agronegócio, o trabalho de Mzembe et al. (2015), feito a partir de um estudo de caso de uma empresa do setor de chá, identificou os valores da companhia e a ação dos diretores como principais fatores determinantes das ações de RSC. McDaniel, Cadman \& Malone (2016) identificaram que existem muitas ações de RSC realizadas pela indústria no tabaco em Malawi e Tanzânia, dos países africanos que estão entre os maiores produtores da planta. Segundos eles, isso pode fortalecer a relação entre as empresas e os agricultores. Na cadeia do cacau, Silva et al. (2018) identificaram inúmeras ações de multinacionais em Costa do Marfim e Gana, os dois países que mais produzem cacau no mundo.

\subsection{Instituições e Responsabilidade Social Corporativa}

De acordo com Brammer, Jackson e Matten (2012), o crescente interesse pela teoria institucional nas pesquisas em administração tem influenciado a sua adoção em estudos sobre RSC, isso se dá pelos benefícios que as lentes desta teoria podem trazer.

Para Campbell (2007), grande parte da literatura sobre RSC ainda não explora se as condições institucionais interferem na adoção de práticas socialmente responsáveis pelas empresas. O autor afirma que as pesquisas, em geral, estão voltadas para o desempenho financeiro das empresas. Algumas exceções são os estudos voltados para como os direitos de propriedade e as formas de regulação estatal afetam o comportamento socialmente responsável adotado pelas organizações, como as instituições normativas e culturais influenciam ações de 
RSC pelas empresas e se as corporações atendem aos requisitos das partes interessadas (teoria dos Stakeholders).

Ainda segundo Campbell (2007), outros pesquisadores desenvolvem estudos com comparativos transnacionais acerca da RSC, os resultados auxiliam na compreensão de como a variação das instituições presentes em cada país alteram o grau de influência das partes interessadas nos gestores.

Um exemplo de trabalho que adota a visão institucionalista para explicar a diferença na adoção da RSC entre os países e o porquê desta diferenciação é o desenvolvido por Matten e Moon (2008). Segundo os autores, os países caracterizados por instituições fracas e má gestão delegam, frequentemente, as responsabilidades a agentes privados. Outro ponto observado diz respeito às pressões institucionais sofridas pelas empresas para atender demandas relacionadas ao meio-ambiente, saúde, segurança e direitos humanos em suas operações globais. Diante disto, a RSC oferece um contexto normativo e institucional para que as empresas assumam responsabilidades sociais.

Já a pesquisa de Brammer, Jackson e Matten (2012) tem o intuito de avaliar as contribuições da teoria institucional para a compreensão da RSC como um modelo de governança. De acordo com os autores, a RSC é definida pelas expectativas da sociedade. A natureza histórica e política das instituições interferem para a criação de uma forma particular de interação entre negócios e sociedade.

Campbell (2007) analisou as condições institucionais que incentivam as empresas a se comportarem de forma socialmente responsável. Os resultados apontam que as corporações estão mais propensas a agirem de forma responsável quando estão inseridas em ambientes com forte regulação estatal, com autorregulações industriais coletivas e com monitoramento de ONGs ou outros órgãos independentes. Estes ambientes institucionais normativos encorajam o comportamento socialmente responsável. Os autores complementam que as instituições são fundamentais para o comprometimento das organizações com as práticas de RSC.

O trabalho de Hsieh (2009) propõe que as multinacionais têm a responsabilidade de promover e melhorar as instituições nos países em que atuam e que, por ventura, careçam de boas instituições. O autor propõe que esta promoção está atrelada ao dever de não impactar negativamente o país acolhedor, além das empresas não ignorarem a influência de suas atividades sobre os regimes políticos.

Percebe-se que os estudos desenvolvidos, até o momento, consideram o papel das instituições e suas influências diretamente nas organizações. Os estudiosos utilizam as instituições formais e informais para a explicar, por exemplo, sua influência na adoção de práticas de RSC pelas empresas, como as instituições presentes no ambiente estimulam comportamentos socialmente responsáveis e as diferenças nas práticas responsáveis desenvolvidas em diversas regiões, impulsionada pelas instituições presentes em cada local. Apesar de ser utilizada em variados estudos sobre RSC, constata-se que ainda não foram exploradas as possibilidades de pesquisas sobre a interferência das instituições em países que constituem o elo da cadeia produtiva das organizações, e como esta intervenção estimula a adoção e direcionamento de práticas socialmente responsáveis pelas empresas para estes países. 


\section{METODOLOGIA}

Trata-se de uma pesquisa qualitativa, com objetivos descritivos e explicativos (Gil, 2002). Os dados e informações utilizados para analisar o ambiente institucional da cafeicultura africana foram obtidos por meio de pesquisa bibliográfica. Foram consultadas diversas fontes com o objetivo de descrever a evolução da atividade na região partir da década de 1960. A pesquisa bibliográfica foi complementada com algumas estatísticas do período em questão. Com isso, foi possível construir um breve panorama histórico. Essa etapa foi descritiva, com o intuito subsidiar a análise posterior.

Como amostra, foram selecionados os países africanos que estavam entre os dez maiores produtores mundiais na década de 1960. Quatro países do continente atenderam a esse critério: Angola, Costa do Marfim, Etiópia e Uganda.

Para a análise sobre as ações de RSC, foi utilizada a pesquisa documental. Foram analisados os relatórios corporativos e web sites institucionais de três empresas multinacionais de café industrializado que atuam na África, a saber Nestlé, Starbucks e Jacobs Douwe Egberts. A escolha delas se deu por estarem entre as maiores compradoras de café do mundo e por disponibilizarem informações sobre ações de Responsabilidade Social Corporativa voltadas para a cafeicultura. Foram consultados os documentos publicados entre os anos de 2012 e 2016 . O Quadro 1 apresenta a relação de documentos analisados.

Quadro 1: Relação de documentos analisados.

\begin{tabular}{|c|c|c|}
\hline Empresa & $\begin{array}{c}\text { Tipo de } \\
\text { Documento }\end{array}$ & Título \\
\hline \multirow{7}{*}{ Nestlé } & Relatório & Nestlé in Society (2012) \\
\hline & Relatório & Nestlé in Society (2013) \\
\hline & Relatório & Nestlé in Society (2014) \\
\hline & Relatório & Nestlé in Society (2015) \\
\hline & Relatório & Nespresso Ecolaboration: Full Term Report 2009-2013 \\
\hline & Relatório & $\begin{array}{l}\text { Project background: Expanding the AAA Sustainable Quality } \\
\text { Program in Ethiopia and Kenya. }\end{array}$ \\
\hline & Web Site & $\begin{array}{c}\text { Nespresso Qualidade Sustentável } \\
\text { https://www.nespresso.com/br/pt/our-choices/qualidade- } \\
\text { sustentavel }\end{array}$ \\
\hline \multirow{6}{*}{ Starbucks } & Relatório & C.A.F.E. Practices: results assessment - fiscal years 2011-2012 \\
\hline & Relatório & 2012 Global Responsibility Report: Year in Review \\
\hline & Relatório & Starbucks Global Responsibility Report: Goals and Progress 2013 \\
\hline & Relatório & Relatório de Responsabilidade Global 2014 \\
\hline & Relatório & Relatório de Responsabilidade Global 2015 \\
\hline & Web Site & $\begin{array}{c}\text { Starbucks Responsibility } \\
\text { https://www.starbucks.com/responsibility }\end{array}$ \\
\hline $\begin{array}{l}\text { Jacobs Douwe } \\
\text { Egberts }\end{array}$ & Web Site & $\begin{array}{c}\text { Corporate Responsibility } \\
\text { https://www.jacobsdouweegberts.com/CR/ }\end{array}$ \\
\hline
\end{tabular}


As informações dos relatórios foram classificadas e analisadas por meio de uma "análise de conteúdo com grade fechada" (Vergara, 2012). A análise de conteúdo é uma técnica que permite identificar o que está sendo dito a respeito de determinado tema, podendo ser empregada em documentos. O tipo de análise de "grade fechada" é aquele em que as categorias pertinentes ao objetivo do estudo são definidas preliminarmente pelos pesquisadores (Vergara, 2012).

Para atender ao objetivo deste trabalho, a análise dos relatórios foi feita com base na seguinte categoria: ações de RSC que tenham como objetivo beneficiar os cafeicultores africanos. Dentro dessa categoria, foram estabelecidas três subcategorias: programas destinados ao treinamento dos cafeicultores, auxílio para as comunidades rurais e promoção da sustentabilidade. Todas as informações presentes nos relatórios alinhadas com essa categoria foram selecionadas e examinadas, o que permitiu compor o quadro de ação das multinacionais.

Por fim, os resultados da pesquisa bibliográfica e da análise de conteúdo foram interpretados por "emparelhamento", que consiste em associa-los ao referencial teórico utilizado (Vergara, 2012).

\section{RESULTADOS}

\subsection{Ambiente institucional da cafeicultura africana}

Na safra 1964/1965, a África tinha 4 países entre os 10 maiores produtores mundiais, com destaque para a Costa do Marfim (3을 e Angola (4ํ). No entanto, nas décadas seguintes, somente a Etiópia apresentou um crescimento expressivo no total de café produzido. Embora a produção de Uganda em 2014/2015 seja maior que nas décadas anteriores, ela está em um patamar próximo ao observado em 1974/1975. Os outros países apresentaram grandes reduções no período, sendo que a cafeicultura angolana praticamente desapareceu. A Tabela 1 apresenta a produção destes países em intervalos de dez anos a partir de 1964/1965.

Tabela 1: Evolução da produção de café nos países estudados, em milhões de sacas de 60 kg.

\begin{tabular}{ccccccc}
\hline País & $\mathbf{1 9 6 4 / 1 9 6 5}$ & $\mathbf{1 9 7 4 / \mathbf { 1 9 7 5 }}$ & $\mathbf{1 9 8 4 / \mathbf { 1 9 8 5 }}$ & $\mathbf{1 9 9 4 / 1 9 9 5}$ & $\mathbf{2 0 0 4 / 2 0 0 5}$ & $\mathbf{2 0 1 4 / 2 0 1 5}$ \\
\hline Angola & 2,49 & 3,19 & 0,23 & 0,10 & 0,02 & 0,03 \\
Costa do & 3,34 & 4,49 & 4,61 & 3,73 & 1,80 & 1,40 \\
Marfim & & & & & & \\
Etiópia & 2,42 & 2,49 & 2,59 & 3,80 & 4,07 & 6,48 \\
Uganda & 2,45 & 3,33 & 2,80 & 3,10 & 2,69 & 3,55 \\
\hline
\end{tabular}

Fatores institucionais podem explicar a decadência da cafeicultura africana. O caso mais emblemático é o de Angola, onde a maioria das lavouras de café pertenciam aos colonizadores portugueses. Entre 1963 e 1975, ocorreu a guerra de independência, que teve como resultado a saída dos agrônomos e produtores portugueses, que eram responsáveis por $70 \%$ da produção (Bellachew, 2015). Logo em seguida teve início uma guerra civil entre dois grupos políticos. 0 
conflito durou 27 anos, tendo sido encerrado apenas em 2002. Desde então, o país é governado por Jose Eduardo dos Santos, líder de um dos lados envolvidos na guerra. Estima-se que 1,5 milhão de pessoas morreram e outras 4 milhões se tornaram refugiadas. A guerra destruiu a infraestrutura cafeeira dos país, cuja safra 1974/1975 foi a última colhida em condições normais. A safra seguinte foi pouco maior que 1 milhão de sacas; em 1979/1980 caiu para apenas 260 mil. Atualmente, cafeicultura angolana possui diversos fatores limitantes, como a falta de infraestrutura e assistência técnica, baixo investimento em pesquisa e falta de recursos para os cafeicultores investirem (Bellachew, 2015). Segundo o autor, esses fatores dependem da ação do governo para serem superados, algo que ainda não ocorreu.

A Costa do Marfim passou por um longo período de paz após a sua independência da França, ocorrida em 1960. O país tem o cacau como principal produto de exportação, mas até a década de 1990 também era um grande produtor de café. Em 1999 ocorreu o primeiro golpe de estado do país, seguido por uma guerra civil em 2002. Os conflitos diminuíram em 2004, mas o país ficou dividido em dois: o norte, controlado por rebeldes; e o sul, sob controle do governo. A reunificação política deveria ocorrer em 2010, mas novos conflitos tiveram início e se estenderam até 2011. Segundo o USDA (2017), o país produziu uma média de 3,6 milhões de sacas por ano durante a década de 1990; na década seguinte, ela caiu para 2,6 milhões; no período entre 2010/2011 e 2015/2016, ficou em 1,6 milhão. Além da instabilidade política nos últimos anos, a comercialização do café marfinense, tanto no mercado interno quanto no externo, é controlada pelo governo (ICO, 2015).

Uganda obteve a independência do Reino Unido em 1962, mas o território era ocupado por diferentes etnias, o que dificultou a estabilidade política da nova nação. Entre 1971 e 1979 o país foi governado pelo ditador Idi Amin, responsável por perseguir e matar cerca de 300 mil cristãos. A economia ugandense foi destruída e a produção de café diminuiu $35 \%$ sob o seu governo. Ainda assim, uma elevação nas cotações internacionais, ocasionada por uma geada que destruiu muitas lavouras no Brasil, ajudou a financiar a vida luxuosa do ditador (Pendergrast, 2010). Após a deposição de Amin, o país foi governado por Milton Obote (1980-1985), mas seu governo foi marcado por guerrilhas e violações dos direitos humanos, o que resultou em $100 \mathrm{mil}$ mortes. Reformas permitiram o crescimento da economia a partir de 1990, mas Uganda ainda é uma nação pobre. Atualmente, os principais entraves ao seu desenvolvimento são infraestrutura inadequada de transporte e energia, irresponsabilidade fiscal e corrupção (Central Intelligence Agency - CIA, 2017).

A Etiópia foi o único país africano a manter sua independência desde o século XIX, exceto por um breve período de domínio italiano entre 1936 e 1941. Em 1971, um golpe militar depôs o imperador Haile Selaisse, que governava desde 1930. Então, teve início o governo socialista de Mengistu Mariam, líder militar que nacionalizou propriedades, perseguiu opositores e era apoiado pela União Soviética e Cuba. As antigas elites do país iniciaram uma resistência armada e voltaram ao poder em 1991. Atualmente, a Etiópia é um dos países mais pobres do mundo, embora tenha obtido grande crescimento do PIB nos últimos anos (CIA, 2017). Na política, o regime atual é de partido único, ou seja, não existe democracia, e a economia é parcialmente planejada. 
Segundo a ICO (2015), as lavouras africanas usam pouca tecnologia. A maioria dos cafeicultores possui baixa escolaridade e nenhum acesso ao crédito. Existem organizações de pesquisa governamentais, mas elas contam com recursos insuficientes para atenderem todas as demandas do setor. A esses problemas somam-se outros mais amplos, como a falta de infraestrutura e os baixos investimentos em saúde, segurança e educação.

\subsection{Responsabilidade Social Corporativa na cafeicultura africana}

\subsubsection{Nestlé}

A multinacional suíça Nestlé é a maior processadora de café do mundo. Segundo dados do seu relatório de Responsabilidade Social Corporativa referente ao ano fiscal de 2015, a companhia comprou $10 \%$ de todo o café produzido no mundo naquele ano. A Nestlé informa que a sua capacidade de longo prazo para obter café na quantidade e qualidade necessária depende da sustentabilidade da cafeicultura. Esta sustentabilidade é ameaçada por lavouras velhas, doenças, produtividade decrescente, volatilidade dos preços e mudanças climáticas. A companhia reconhece que a maior parte do café é produzida por pequenos cafeicultores, dos quais grande parte já está na terceira idade.

Tendo isto em vista, foram propostas ações para elevar a renda dos cafeicultores, de modo que eles permaneçam na atividade e produzam café nas qualidades e quantidades necessárias. As ações da companhia se dividem em dois programas principais: o Nescafé Plan e o Nespresso AAA Sustainable Quality Program. O Nescafé Plan busca garantir o suprimento de café utilizado nos produtos da marca Nescafé, enquanto o Nespresso AAA é exclusivo para os cafés utilizados pela Nespresso, uma subsidiária da Nestlé que atua no mercado de luxo.

O Nescafé Plan conta com um orçamento de 350 milhões de francos suíços para o período entre 2010 e 2020. O programa já contempla cafeicultores de 19 países em todos os continentes produtores. Os princípios do programa são: a) proporcionar que os cafeicultores sejam mais eficientes e produzam café de melhor qualidade; b) fazer com que eles se adequem às normas de verificação 4C, que buscam tornar a cafeicultura mais sustentável; e c) melhorar os aspectos ambientais e sociais das propriedades, levando a melhores padrões de vida.

Dentro do Nescafé Plan, uma das inciativas é o Farmer Connect, que visa encurtar a cadeia de intermediários para aproximar a Nestlé dos cafeicultores. Segundo a empresa, até 2015 um total 211 mil cafeicultores participavam do programa, vendendo a sua produção diretamente para a Nestlé, ou com intermédio de cooperativas e outros parceiros. O Farmer Connect também oferece treinamentos aos cafeicultores e, até 2015, mais de 382 mil foram treinados.

Dentro do escopo de atuação do Nespresso AAA, os produtores são incentivados a produzir café de alta qualidade dentro de normas de sustentabilidade definidas pela Nespresso. Participam do programa 75 mil produtores de 12 países ao redor do mundo. Na África, a companhia trabalha em parceria com a TechnoServe, uma organização sem fins lucrativos que ajuda os cafeicultores a serem mais produtivos, algo que influencia diretamente a renda obtida com a atividade. 
Em 2015, 14 mil cafeicultores etíopes e 6,8 mil cafeicultores quenianos passaram a fazer parte do programa. O objetivo da companhia com estes países é suprir sua demanda por grãos de qualidade e reduzir a pobreza. No entanto, a Nespresso aponta que existem dificuldades na cadeia de suprimentos dos dois países que incluem a pobreza dos cafeicultores, falta de investimentos e baixo nível de treinamento. Além disso, a comercialização do café é fortemente regulada em ambas as nações, o que dificulta o estabelecimento de um relacionamento de compra direta entre a Nestlé e os produtores rurais.

Uma das ações da Nespresso no continente é a reconstrução do setor cafeeiro no Sudão do Sul. Trata-se de um país que obteve a independência em 2011, após uma guerra civil no Sudão (1983-2005) que deixou 2 milhões de mortos e 4 milhões de refugiados. Mesmo agora, a situação do Sudão do Sul é complicada, visto que novos conflitos, dentro do país, tiveram início em 2013. Após um acordo de paz, em 2015, a violência, que ocorre entre antigos aliados políticos, recomeçou em 2016.

De acordo com a Nespresso, ela foi a primeira empresa de café a se estabelecer no novo país. Em parceria com a Technoserve, foram criadas três cooperativas nos primeiros 18 meses de trabalho, o que permitiu que o país exportasse café pela primeira vez em mais de 30 anos. 0 objetivo da Nespresso é reduzir a pobreza de 2 mil cafeicultores, mas os conflitos dificultam a ação constantemente.

\subsubsection{Starbucks}

A Starbucks, em parceria com a Conservation International, criou o programa Coffee and Farmer Equity (C.A.F.E.). Trata-se de um conjunto de normas sociais, ambientais e econômicas que orientam as compras de café da Starbucks. Para se adequar, os cafeicultores e outros agentes da cadeia precisam cumprir com mais de 200 critérios que buscam garantir a sustentabilidade da produção em todas as duas dimensões.

No âmbito social, são verificados salários, educação, saúde, benefícios, direitos humanos e condições de vida dos cafeicultores, trabalhadores e famílias destes. No aspecto ambiental, são verificados indicadores acerca do solo, água, energia, desperdício, uso de agroquímicos, preservação das matas e da vida selvagem. No nível econômico, são verificadas a equidade dos pagamentos, a comprovação das operações de compra, a rastreabilidade dos grãos, a viabilidade no longo prazo e a qualidade da bebida.

Segundo a companhia, o cumprimento de todos esses itens é verificado por uma organização independente para assegurar sua credibilidade. Em 2015, 99\% de todo o café adquirido pela Starbucks estava certificado dentro das normas do C.A.F.E. Dados referentes aos anos fiscais de 2011 e 2012 mostram que, a cada ano, 440 mil trabalhadores empregados nas lavouras de café certificadas, em média, receberam salários acima do mínimo vigente em cada região.

Outra ação da Starbucks com impacto direto sobre os cafeicultores é a concessão de empréstimos. O dinheiro pode ser utilizado, por exemplo, para financiar a renovação das lavouras antigas. Em 2014, foram concedidos US\$ 16,3 milhões e, em 2015, US\$ 21,3 milhões. 
Dados de 2011 mostram que, na África, o programa C.A.F.E abrangia mais de 40 mil propriedades rurais, a grande maioria caracterizadas como pequenas. Não há dados mais recentes sobre o número de participantes.

Na África, a empresa atua nos países do leste do continente. Em 2012, comprou café de Zâmbia, Tanzânia, Ruanda, Burundi, Quênia e Etiópia. A Starbucks também possui centros de apoio aos cafeicultores em Tanzânia, Ruanda e Etiópia.

Na Tanzânia, a companhia trabalhou com a Heifer International para ajudar os cafeicultores a terem acesso a água limpa e a diversificarem suas fontes de renda, com a introdução de gado leiteiro nas propriedades. Em 2014, a empresa passou a comprar café do Congo. Até 2015, 4,5 mil cafeicultores haviam sido beneficiados. Segundo um relatório, a renda deles triplicou.

\subsubsection{Jacobs Douwe Egberts}

Jacobs Douwe Egberts (JDE) é uma companhia jovem, formada a partir da aquisição dos ativos de café da Mondelez International e da Master Blenders pela JAB Holding. Antes das aquisições, as duas companhias possuíam relatórios de RSC bem estruturados, mas a nova companhia apresenta poucas informações no seu web site.

Na Etiópia, a companhia trabalha em quatro linhas de ação:

a) Aumentar a produtividade dos cafeicultores. Juntamente com a TechnoServe, foi criado o projeto Farm College, que oferece treinamento aos cafeicultores. A duração prevista é de dois anos e são realizadas sessões mensais de capacitação. No país, 16 mil produtores já participaram de pelo menos duas sessões.

b) Criar estações de beneficiamento de café que sejam sustentáveis. Também em parceria com a TechnoServe, o trabalho busca registrar e treinar as estações de beneficiamento de café em práticas sustentáveis.

c) Engajamento com mulheres e jovens. A companhia oferece atenção especial a participação de mulheres e jovens nos treinamentos.

d) Apoio ao desenvolvimento da rastreabilidade do café. A JDE trabalha junto com a Bolsa do Café da Etiópia e ONGs internacionais para viabilizar a rastreabilidade dos cafés etíopes.

Em Uganda, a empresa também definiu quatro linhas principais de atuação:

a) Estabelecer e fortalecer organizações de cafeicultores. Com o poio de ONGs parceiras, 797 organizações de cafeicultores já foram estabelecidas no país.

b) Aumentar a produtividade e sustentabilidade das lavouras. Foram criadas escolas de campo para treinar os cafeicultores. $96 \%$ dos participantes afirmam terem melhorado as práticas de gestão após os treinamentos; a produtividade por árvore (grãos em coco) aumentou de menos de 1 quilo para 2,7 quilos; e a utilização de podas aumentou de $77 \%$ para $92 \%$.

c) Empoderar mulheres de famílias de cafeicultores. 7,8 mil pessoas já participaram de seminários sobre gênero e 2,7 mil casais se registraram para serem agentes de mudança em suas comunidades. 
d) Melhorar o acesso dos cafeicultores a serviços. Juntamente com parceiros, há um trabalho para aumentar o acesso dos cafeicultores ao microcrédito, além de criar ligações entre os cafeicultores e outras organizações que ajudem eles a comprar insumos agrícolas. Também foram criadas 38 associações de poupança e empréstimos em comunidades do país.

\section{DISCUSSÃO DOS RESULTADOS}

Os dados da produção de café na África mostram uma tendência de queda desde a década de 1960. Quando analisados os números dos quatro maiores produtores do continente na safra 1964/1965, verifica-se também uma redução no volume colhido, exceto na Etiópia. A história recente de todos eles foi marcada por conflitos violentos e instabilidade institucional. Golpes de Estado, guerras civis e governos ditatoriais foram frequentes na África no período pósindependência.

Segundo a Nova Economia Institucional, países que não garantem as liberdades civis e políticas tendem a desenvolver instituições extrativistas, ou seja, as instituições são apropriadas por uma elite que utiliza elas para seus fins particulares (Acemoglu \& Robinson, 2012). Além disso, a instabilidade institucional, que pode decorrer de conflitos internos, afasta investimentos e prejudica a coordenação do setor privado, além dos danos causados aos cidadãos (Easterly, 2014).

Os dados obtidos sugerem que a cafeicultura dos principais produtores da África está inserida em um ambiente institucional vulnerável. Com isso, as ações de Responsabilidade Social Corporativa de companhias multinacionais podem ser uma alternativa para preencher o "vazio institucional" do Estado.

Quase todos os países produtores de café sofrem com vazios institucionais, ou seja, lacunas no ecossistema de mercado que interferem na prosperidade das empresas. Estes vazios compreendem falhas em infraestrutura, sistemas legislativos fracos, falta de acesso à educação ou baixa qualidade educacional e restrições a financiamentos. Todos estes aspectos são fundamentais para a promover a saída dos pequenos produtores da pobreza (Specialty Coffee Association of America - SCAA, 2013).

Embora essa seja uma condição encontrada em vários países, os números da produção mundial mostram que a África possui o cenário mais crítico. Por sua vulnerabilidade, a cafeicultura do continente passa a atrair ações de RSC da indústria do café. Pelo menos uma companhia, a Nestlé, informa aos seus stakeholders que seus negócios com café dependem da melhoria das condições de trabalho e renda dos cafeicultores.

Assim, as ações de RSC atendem a dois propósitos distintos. O primeiro é o cumprimento das novas demandas sociais do mundo contemporâneo, em que a organização não deve agir apenas pelo lucro. $\mathrm{O}$ segundo compreende a garantia do abastecimento da matéria-prima, o café. Convém notar que ações de RSC podem ser direcionadas a diferentes tipos de comunidades, urbanas ou rurais, mas neste caso específico elas vão de encontro aos cafeicultores. 
No entanto, o número de produtores beneficiados em cada país ainda é pequeno em comparação com o total. Por exemplo, Nespresso e JDE, juntas, beneficiaram cerca de 30 mil cafeicultores etíopes, o que representa apenas 1,2\% do total no país (ICO, 2015). Além disso, as três companhias analisadas apresentam poucos dados que permitam uma mensuração do impacto real das suas ações sobre a vida dos produtores.

Para Collier e Dercon (2014) o grande número de pequenos agricultores africanos é reflexo de uma economia pouco desenvolvida. Segundo os autores, o crescimento econômico depende do desenvolvimento das áreas urbanas, o que criará novas oportunidades em trabalhos mais produtivos. Ao mesmo tempo, o processo de migração para as cidades cria maior demanda por alimentos, o que estimula o desenvolvimento da agricultura local. Eles afirmam que para isso ocorrer é necessário um ambiente institucional capaz de fomentar essas mudanças e assegurar os direitos de propriedade dos pequenos agricultores.

\section{CONCLUSÃO}

O objetivo do artigo foi investigar as causas da baixa produção de café na África e os determinantes da ação das empresas multinacionais no setor. Para tanto, utilizou a Nova Economia Institucional e a literatura de Responsabilidade Social Corporativa.

Os dados analisados sugerem uma relação entre o ambiente institucional dos quatro países africanos selecionados e o fraco desempenho da cafeicultura na região, bem como uma relação entre o ambiente institucional e as ações de RSC de empresas multinacionais. A instabilidade política e social, caracterizada por conflitos armados e violações dos direitos humanos, cria condições desfavoráveis ao desenvolvimento econômico, uma possibilidade amparada teoricamente pela Nova Economia Institucional. Com isso, a cafeicultura africana entrou declínio a partir da década de 1960. A situação precária dos cafeicultores da região abre margem para ações de RSC das grandes empresas de café, que podem comunicar tais ações aos stakeholders e, também, estimulam a produção local. Neste contexto, as empresas atuam no vazio institucional deixado Estado, oferecendo serviços que seriam de responsabilidade dele, como assistência técnica, crédito e até educação.

Estudos futuros poderão averiguar, a partir de fontes primárias, o impacto das ações de RSC sobre a renda dos cafeicultores africanos, aspecto que os relatórios das empresas não detalham. Também é preciso compreender melhor o que prevalece na decisão das empresas em apoiar os cafeicultores.

A principal limitação do estudo está no uso de fontes secundárias para caracterização das ações de RSC das empresas analisadas. Os relatórios e outras fontes publicadas pelas próprias organizações oferecem informações valiosas, porém, limitadas.

\section{REFERÊNCIAS}

Acemoglu, D. (2008). Introduction to modern economic growth. Princeton University Press.

Acemoglu, D., Robinson, J. (2012). Por que as nações fracassam: As origens do poder, da prosperidade e da pobreza. São Paulo: Elsevier. 
Auer, R. A. (2013). Geography, institutions, and the making of comparative development. Journal of Economic Growth, 18(2), 179-215.

Baron, D. P. (2001). Private politics, corporate social responsibility, and integrated strategy. Journal of Economics \& Management Strategy, 10 (1), 7-45.

Barone, G., Mocetti, S. (2014). Natural disasters, growth and institutions: A tale of two earthquakes. Journal of Urban Economics, 84, 52-66.

Belasen, A. R., Hafer, R. W. (2012). Well-being and economic freedom: Evidence from the States. Intelligence, 40(3), 306-316.

Bellachew, B. (2015). A brief account of coffee production in angola: a quick assessment report. Recuperado em 31 de janeiro, 2018, de http://www.iacooiac.org/sites/default/files/travel_report_no_11_-_angola.pdf.

Bertoncello, S. L. T., Chang Jr, J. (2007). A importância da responsabilidade social corporativa como fator de diferenciação. FACOM-Revista da Faculdade de comunicação da FAAP, 17, 7076.

Blau, B. M., Brough, T. J., Thomas, D. W. (2014). Economic freedom and the stability of stock prices: A cross-country analysis. Journal of International Money and Finance, 41(C), 182-196.

Brammer, S., Jackson, G., Matten, D. (2012). Corporate social responsibility and institutional theory: New perspectives on private governance. Socio-Economic Review, 10(1), p. 3-28.

Bueno, N. P. (2004). Lógica da ação coletiva, instituições e crescimento econômico: uma resenha temática sobre a Nova Economia Institucional. EconomiA, 5(2), 361-420.

Bureau de Inteligência Competitiva do Café. (2015). Relatório Internacional de Tendências do Café, 4, n.4 \& 5. Recuperado em 30 de agosto, 2016, de http://www.icafebr.com.br/publicacao2/Relatorio\%20v4\%20n4\%20e\%205.pdf

Campbell, J. L. (2007). Why would corporations behave in socially responsible ways? An institutional theory of corporate social responsibility. Academy of management Review, 32(3), 946-967.

Carroll, A. B. (1979). A three-dimensional conceptual model of corporate performance. Academy of management review, 4(4), 497-505.

Carroll, A. B. Corporate social responsibility evolution of a definitional construct. Business \& Society, 38(3), 268-295.

Central Intelligence Agency. (2017). The World Factbook. Recuperado em 30 de junho, 2017, de https://www.cia.gov/library/publications/the-world-factbook/.

Collier, P., Dercon, S. (2014). African Agriculture in 50 Years: Smallholders in a Rapidly Changing World? World Development, 63, 92-101.

Conceição, O. A. C. (2002). Instituições, crescimento e mudança na ótica institucionalista. Porto Alegre: Heuser, Fundação de Economia e Estatística Siegfired Emanuel.

Costa. M. A. N. (2005). Fazer o bem compensa? Uma reflexão sobre a responsabilidade social empresarial. Revista Crítica de Ciências Sociais, 73, 67-89.

Dahlsrud, A. (2008). How corporate social responsibility is defined: an analysis of 37 definitions. Corporate Social Responsibility and Environmental Management, 15 (1), 1-13. 
Davis, L. E., North, D. C., Smorodin, C. (1971). Institutional change and American economic growth. London: Cambridge University Press.

Easterly, W. (2014). The Tyranny of Experts: Economists, Dictators, and the Forgotten Rights of the Poor. New York: Basic Books.

Fernandes, J. M. (2014). A responsabilidade social das empresas no contexto da agricultura familiar. Um estudo de caso: as plantações de cacau na Costa do Marfim. SOCIUS Working Papers. Recuperado em 22 de agosto, 2016, de http://www.repository.utl.pt/handle/10400.5/7585.

Fiani, R. (2011). Cooperação e Conflito: instituições e desenvolvimento econômico. São Paulo: Elsevier.

Frynas, J. G., Yamahaki, C. (2016). Corporate social responsibility: review and roadmap of theoretical perspectives. Business Ethics: A European Review, 25(3): 258-285.

Garriga, E., Melé, D. (2004). Corporate social responsibility theories: Mapping the territory. Journal of Business Ethics, 53(1-2), 51-71.

Gehring, K. (2013). Who Benefits from Economic Freedom? Unraveling the Effect of Economic Freedom on Subjective Well-Being. World Development, 50, 74-90.

Gil, A. C. (2002). Como elaborar projetos de pesquisa (4. ed.) São Paulo: Atlas.

Hall, J. C., Lawson, R. A. (2014). Economic Freedom of the World: an accounting of the literature. Contemporary Economic Policy, 32, (1), 1-19.

Heo, U., Hahm, S. D. (2015). Democracy, Institutional Maturity, and Economic Development. Social Science Quarterly, 96(4), 1041-1058.

Herrera-Echeverri, H., Haar, J., Estévez-Bretón, J. B. (2014). Foreign direct investment, institutional quality, economic freedom and entrepreneurship in emerging markets. Journal of Business Research, 67(9), 1921-1932.

Hsieh, N. (2009). Does global business have a responsibility to promote just institutions? Business Ethics Quarterly, 19 (02), 251-273.

International Coffee Organization. (2015). Sustainability of coffee sector in Africa. Recuperado em 15 de julho, 2017, de http://www.ico.org/documents/cy2014-15/icc-114-5-r1e-overviewcoffee-sector-africa.pdf.

International Coffee Organization. (2017a). Historical Data on the Global Coffee Trade: Total Production. Recuperado em 16 de dezembro, 2017, de http://www.ico.org/historical/1990\%20onwards/PDF/1a-total-production.pdf.

International Coffee Organization. (2017b). Historical Data on the Global Coffee Trade: Imports. Recuperado em 16 de dezembro, 2017, de http://www.ico.org/historical/1990\%20onwards/PDF/2b-imports.pdf.

International Coffee Organization. (2017c). International Coffee Agreement 2007. Recuperado em 16 de dezembro, 2017, de http://www.ico.org/ica2007.asp.

Klein, P. G. (1998). New Institutional Economicsç. Recuperado em 8 de junho, 2017, de https://papers.ssrn.com/sol3/papers.cfm?abstract_id=115811. 
Kreitlon, M. P. (2004). A ética nas relações entre empresas e sociedade: fundamentos teóricos da responsabilidade social empresarial. XXVIII Encontro Anual da Anpad, Curitiba.

Lee, M.D. P. (2008). A review of the theories of corporate social responsibility: Its evolutionary path and the road ahead. International Journal of Management Reviews, 10 (1), 53-73.

McDaniel, P. A., Cadman, R., Malone, E. (2016) Shared vision, shared vulnerability: a contente analysis of corporate social responsibility information on tobacco industry websites. Preventine Medicine, 89, 337-344.

Matten, D., Moon, J. (2008). "Implicit" and "explicit" CSR: a conceptual framework for a comparative understanding of corporate social responsibility. Academy of Management Review, 33 (2), 404-424.

Ménard, C., Shirley, M. M. (2005). Introduction. In: Ménard, C., Shirley, M. M. (Orgs.). Handbook of New Institutional Economics. Dordrecht: Springer.

Mzembe, A. N., Lindgreen, A., Maon, F., Vanhamme, J. (2016). Investigating the Drivers of Corporate Social Responsibility in the Global Tea Supply Chain: A Case Study of Eastern Produce Limited in Malawi. Corp. Soc. Responsib. Environ. Mgmt., 23(3), 165-178

Neudorfer, N. (2015). Development, democracy and corruption: How poverty and lack of political rights encourage corruption. Journal of Public Policy, 35(3), 421-457.

North, D. C. (2010). Desempenho econômico através do tempo. Revista de Direito Administrativo, 255, 13-30.

North, D. C. (1989). Institutions and economic growth: an historical introduction. World Development, 17 (9), 1319-1332.

Pendergrast, M. (2010). Uncommon Grounds: The History of Coffee and How it Transformed our World (2nd ed). New York: Basic Books.

Ponte, S. (2002). The 'Latte Revolution'? Regulation, Markets and Consumption in the Global Coffee Chain. World Development, 30(7), 1099-1122.

Ranganathan, S., Nicolis, S. C., Spaiser, V., \& Sumpter, D. J. (2015). Understanding democracy and development traps using a data-driven approach. Big data, 3(1), 22-33.

Silva, E. C., Azevedo, A. S., Barros, M., Reis, N. D. (2018). Responsabilidade social corporativa na produção de cacau: análise das ações da indústria de chocolate. Revista Gestão e Desenvolvimento, 15(1), 183-204.

Spaiser, V., Ranganathan, S., Mann, R. P., Sumpter, D. J. T. (2014). The dynamics of democracy, development and cultural values. PLOS ONE, 9(6), e0118878.

Specialty Coffee Association of America - SCAA. (2013). A Blueprint to End Hunger in the Coffeelands. Recuperado em 30 de agosto, 2016, de http://scaa.org/PDF/SCAA-whitepaperblueprint-end-hunger-coffeelands.pdf.

Topik, S. (2003). The Integration of the World Coffee Market. In: Clarence-Smith, W. G., Topik, S. The Global Coffee Economy in Africa, Asia, and Latin America 1500-1989. Cambridge: Cambridge University Press.

United States Department of Agriculture. (2017). Production, Supply and Distribution Online. Recuperado em 30 de junho, 2017, de http://apps.fas.usda.gov/psdonline/psdQuery.aspx. 
Van Marrewijk, M. (2003). Concepts and definitions of CSR and corporate sustainability: Between agency and communion. Journal of Business Ethics, 44(2-3), 95-105.

Vergara, S. C. (2012). Método de Pesquisa em Administração (5a ed.). São Paulo: Editora Atlas.

Wang, Q., Dou, J., Jia, S. (2016). A Meta-Analytic Review of Corporate Social Responsibility and Corporate Financial Performance: The Moderating Effect of Contextual Factors. Business \& Scoiety, 55(8), 1083-1121.

Williamson, O. E. (1996). The Mechanisms of Governance. New York: Oxford University Press.

Wood, D. J. (1991). Corporate social performance revisited. Academy of Management Review, 16 (4), 691-718.

World Business Council for Sustainable Development. (1991). Corporate Social Responsibility. Genebra: WBCSD Publications.

Yoon, Y., Gürhan-Canli, Z., Schwarz, N. (2006). The effect of corporate social responsibility (CSR) activities on companies with bad reputations. Journal of consumer psychology, 16(4), 377390. 